\title{
Drawing Essence from Ancient to Nourishing the New-A Study of REN Ping’s Calligraphic Art
}

\author{
YING Yi-wen \\ Zhejiang University of Technology, Hangzhou, China
}

\begin{abstract}
This paper expresses REN Ping's views on calligraphic arts and classical Chinese literature. Calligraphy and literature could not only express ideas, sentiments, and aesthetic charm, but also create harmony in relationships. The study focuses on his calligraphic styles such as Cursive Calligraphy (草书), Regular Script (楷书), Seal Script (管书), running style (行书) and so on. His calligraphic art creation lends a unique classical style to the Chinese movie, and shows a board and wide beauty of nature for pavilion of ZONG XIU in Hangzhou, which draws essence from ancient to nourishing the new. It is widely accepted that REN Ping's accomplishment results from, his accumulation of Chinese traditional culture, his rich knowledge in occidental philosophy and art, his outstanding artistic talents, and from his generosity, forthrightness, and sincerity, and his all-embracing humanistic feelings.
\end{abstract}

Keywords: calligraphic art, REN Ping, lines, stroke techniques, classical Chinese literature, artistic creation

\section{Introduction}

REN Ping's presentation at the Confucius Institute of University of South Carolina in US in 2012 allowed young Americans to enjoy the beauty and mysteriousness of Chinese calligraphy. He held a personal calligraphy exhibition known as the "Works of Chinese Calligraphy and Painting by REN Ping" in Barcelona in Spain in 2011. The rich themes and styles of his calligraphic works make the local people feel very excited. During the "Asian Culture Week" in Berlin in 2003, his calligraphy was on display in the German News Building. After that he was invited by University of Germany to give a lecture titled How Can We Enjoy Chinese Calligraphy. In 1993 he was invited as a visiting professor to give lectures at the Universite de Paris VIII in France, and held his personal calligraphy exhibition in Paris. His calligraphy works have been collected by the National Art Museum of China, the Universite de Paris VIII in France, the Victoria Institute in Germany, the Kobe University in Japan, the University of Melbourne in Australia, the Seoul National University in Korea, and the National Cheng Kung University in Taiwan, and so on.

\section{Chinese Calligraphy and Classical Chinese Literature}

PEN Ping writes,

Permeating the artistic thoughts on calligraphy is the poetry of harmony between man and nature and forgetting of object and self. In addition, the mental status in writing and creating, beneficial to both physical and psychological health,

YING Yi-wen, Ph.D., associate professor, School of Art, Zhejiang University of Technology. 
is able to morph into a good spiritual medicine for the people of today, and supply multiple inspirations for modern artistic creation and cultural creativity. ${ }^{1}$

Calligraphy and literature could not only express ideas, sentiments, and aesthetic charm, but also create harmony in relationships. The contents of calligraphic and literary works are almost dominated by the same cultural feelings and aesthetic charms, which tend to have the calligrapher's mind and hand work in accord, and effect the fusion of calligraphy style and poetic flavor (see Figure 1).

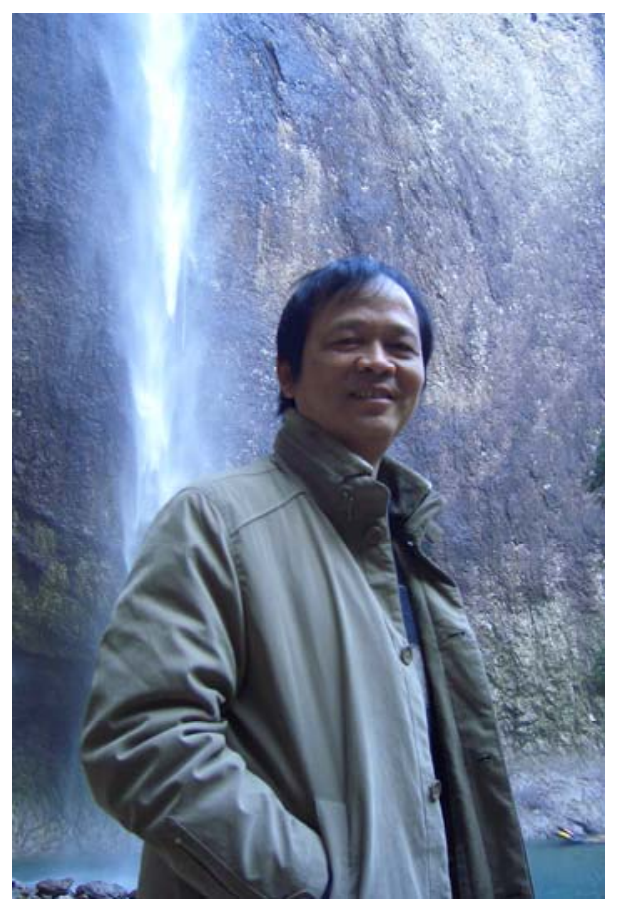

Figure 1. PEN Ping (2012). The Contemporary Academic Calligraphy Masters Portfolio一REN Ping (当代书法学术

名家作品: 任平). Hong Kong: World Culture and Art Press. Title Page.

Chinese calligraphy, classical Chinese literature, and traditional Chinese aesthetics share a lot in common. Buddhist aesthetics seek harmony and unity between individuals and society so as to achieve an ambience of aesthetics beauty. Taoist aesthetics regards nature as the inherent quality of the universe and man and pursues an ambience of aesthetics beauty characterized by the unity of man and nature. Zen aesthetics holds sacred the position and role of the mind and seeks to achieve an ambience of aesthetics beauty that transcends time and space through sudden enlightenment, an ambience of freedom where the subject and the object, the matter and the self are in one. Especially, Chinese theories on paintings in the Tang Dynasty posited that painting and calligraphy share the same source and that mind and calligraphy, and mind and painting are one and the same. In this way, both calligraphy and paintings go through the creative process from the mind to the taoist and to the art. Thus during the Tang Dynasty, the vital importance of the source of the mind and the outside matter for artistic creation is emphasized.

PEN Ping Calligraphy Exhibition titled The Tang Dynasty Style and Its Lingering Charm was held in

\footnotetext{
${ }^{1}$ All quotations attributed to PEN Ping, from a description word of the Chinese Calligraphy Masterpieces Exhibition of the Orchid Pavilion Foreword with the author in Brussels in Belgium.
} 
Hangzhou from 21th June to 5th July in 2014. The exhibition showed the running script, cursive style, clerical script, and other traditional writing scripts as well as many cross-border creative styles. Especially at the opening ceremony, REN Ping was doing on-the-spot calligraphy writing titled A Moonlight-Night on the Spring River, accompanied by harp, an ancient plucked stringed instrument (see Figure 2). The calligraphic work shows his masterful stroke techniques in full, calm, leisurely, natural, but vigorous. The natural fit of calligraphic work and poetry created a flowing beauty that is both glittering and translucent, and a lyrical charm that bewitches the audience into the ancient Chinese art.

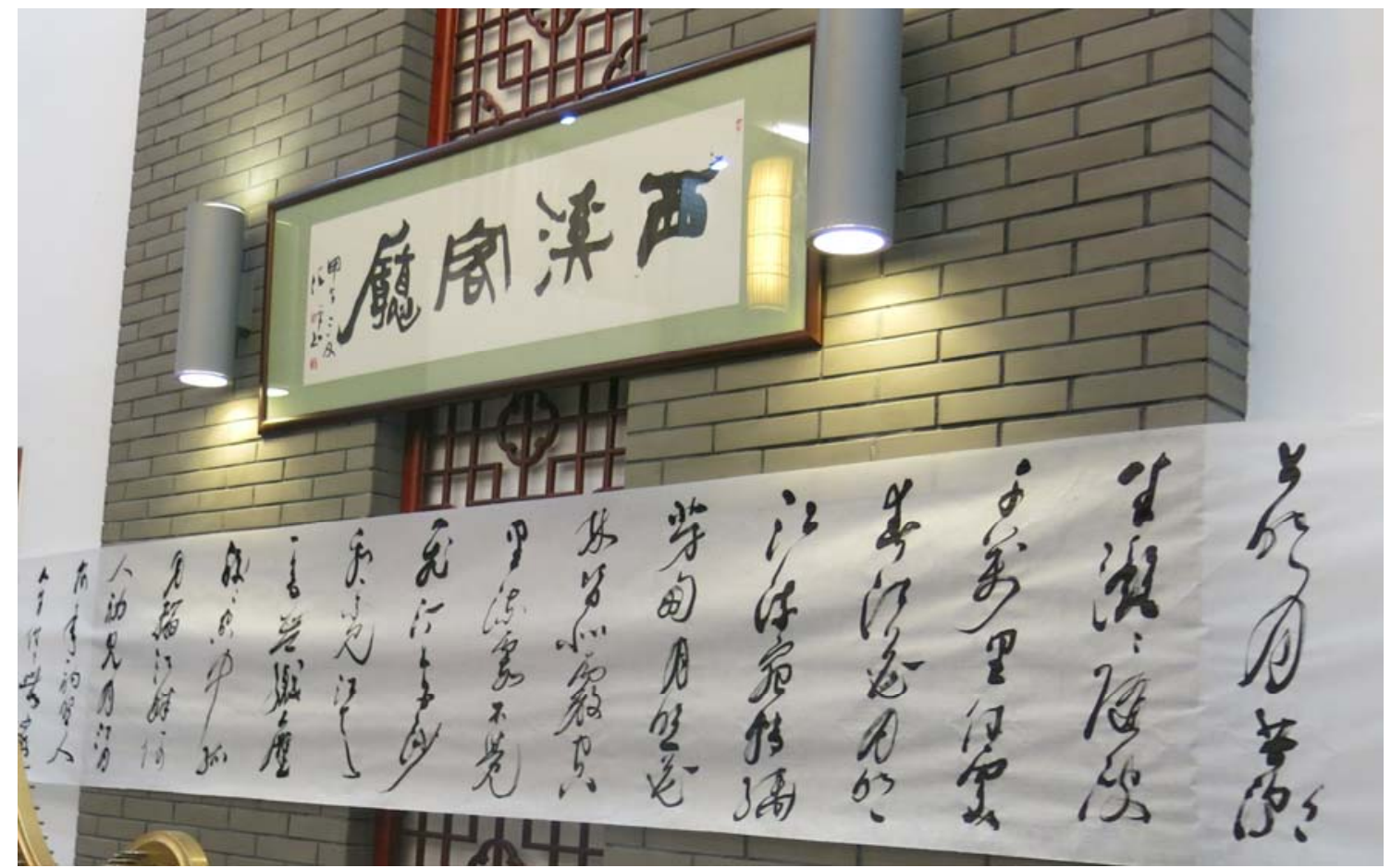

Figure 2. On-the-spot Running Style Writing 行书 titled Poem of ZHANG Ruoxu: A Moonlight-Night on the Spring River (张若虚诗: 春江花月夜) $(1200 \times 70 \mathrm{~cm})$. The photography was taken by author from PEN Ping Calligraphy Exhibition titled The Tang Dynasty Style and Its Lingering Charm in Hangzhou on the 21th June 2014.

\section{Academic Visiting and Calligraphic Communication}

In 2007, REN Ping was invited to Kobe University, Japan for an international conference on the Globalization of Calligraphy and Its Social Contribution. Later, he gave lectures at the University.

As a Chinese calligraphy professor, I often think: What contributions can I make to the current society? My basic idea is as follows: Firstly, calligraphy has unique oriental cultural attributes. The globalization of calligraphy does not mean that calligraphy will have its unique features changed to adapt to the environment, but that it should be made understandable to the general public in the world. Secondly, although the beauty of calligraphy is enjoyable and may touch the hearts and minds of people all over the world, the cultural connotation and life philosophy contained in calligraphy can supply more inspirations and help promote peace and social development. (p. 18) ${ }^{2}$

\footnotetext{
2 REN, P. (2014) Lecture Outline of Kobe University (在日本神户大学的演讲纲要). From the REN Ping Calligraphy and Painting Series (任平书画文丛). Hefei: Anhui Fine Arts Publishing House. p. 18.
} 
An advocate of the concept that "calligraphy inspires intelligence" REN Ping, has long been a famous calligraphy educator. He published calligraphy monographs such as Chinese Calligraphy, Explanations of Clerical Script, The Brush Sings and The Ink Dances, Complete Works of Chinese Calligraphy (Volume Fortieth), Calligraphy for the University, Chinese Calligraphy Collection (The Southern Song Dynasty Artistic Distinction), Direct Solution of Rites, Republic of China Calligraphy Series and so on. He is the professor of the Chinese National Academy of Arts Ministry of Culture and the Department of Arts of Zhejiang University. As the doctoral tutors of the Chinese National Academy of Arts and the Zhejiang University, 20 of masters and doctors have been trained by REN Ping. His personal calligraphy exhibition titled The Rhymes and Styles of Chinese calligraphy in Peking University has been highly praised by the Peking University students and academicians (see Figures 3 and 4).

In 2002, REN Ping was invited to the University of Melbourne to act as a visiting scholar. He held several calligraphic exhibitions at the university and its art gallery, where he gave demonstrations while making a presentation. Some Australian painters saw the creating process of Chinese calligraphy on the spot for the first time, and they cried in amazement, “Chinese lines are gorgeous!” REN Ping is a master in the art and expresses the lines of calligraphy with unique features. His calligraphic lines aim to create a vibrant beauty resulting from sweeping wrap-around and continuous changes. Calligrapher's work pays attention to abstract beauty and the beauty of the art form. It exhibits a varied but balanced guitar body, highlighting the intricate structural continuity of a piece of calligraphy. It also embodies the spirit-resonance of motion in stillness. In calligraphic art, there is a rhythmic beauty running through the calligraphic works, allowing the charm of lines to fully express the calligrapher's creative thoughts and feelings, making them stand out impressively (see Figures 5 and 6).

As this author sees, this is a process of appreciation and invention the Chinese calligraphers go through in the use of brushes, ink, paper, and ink strokes. It represents REN Ping's understanding of how to express a calligrapher's thoughts and feelings through lines and blankness left on paper, and his understanding of brush paintings in general. Furthermore, it reflects the development trend of moving from the cautious to unfolding, from the slow to the speedy, and from the real to the imaginary. His calligraphic works also set store by the unfolding of the personalities of individual artists, seeking to please the eye while enhancing the spirits, and reflect the art aesthetic trend of leisurely beauty and robust delicacy.

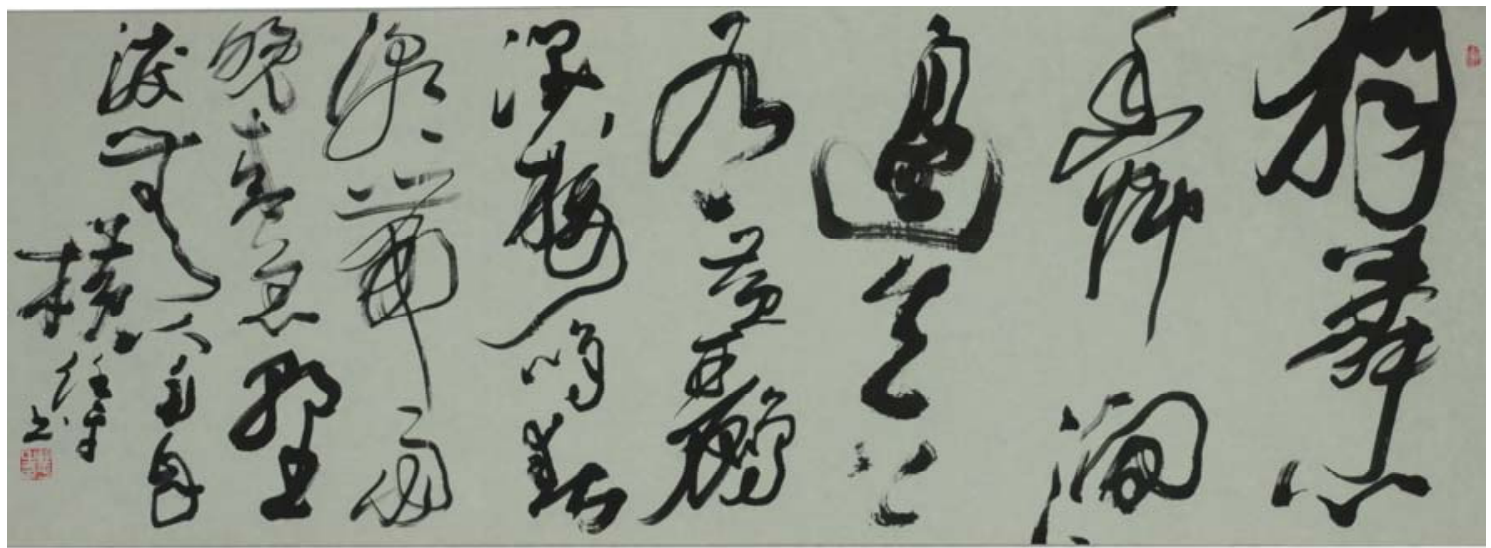

Figure 3. REN Ping's Cursive Calligraphy (草书) titled Poem of WEI Yingwu (韦应物诗) $(120 \times 50 \mathrm{~cm})$. The photography was taken by Author in 2013. 


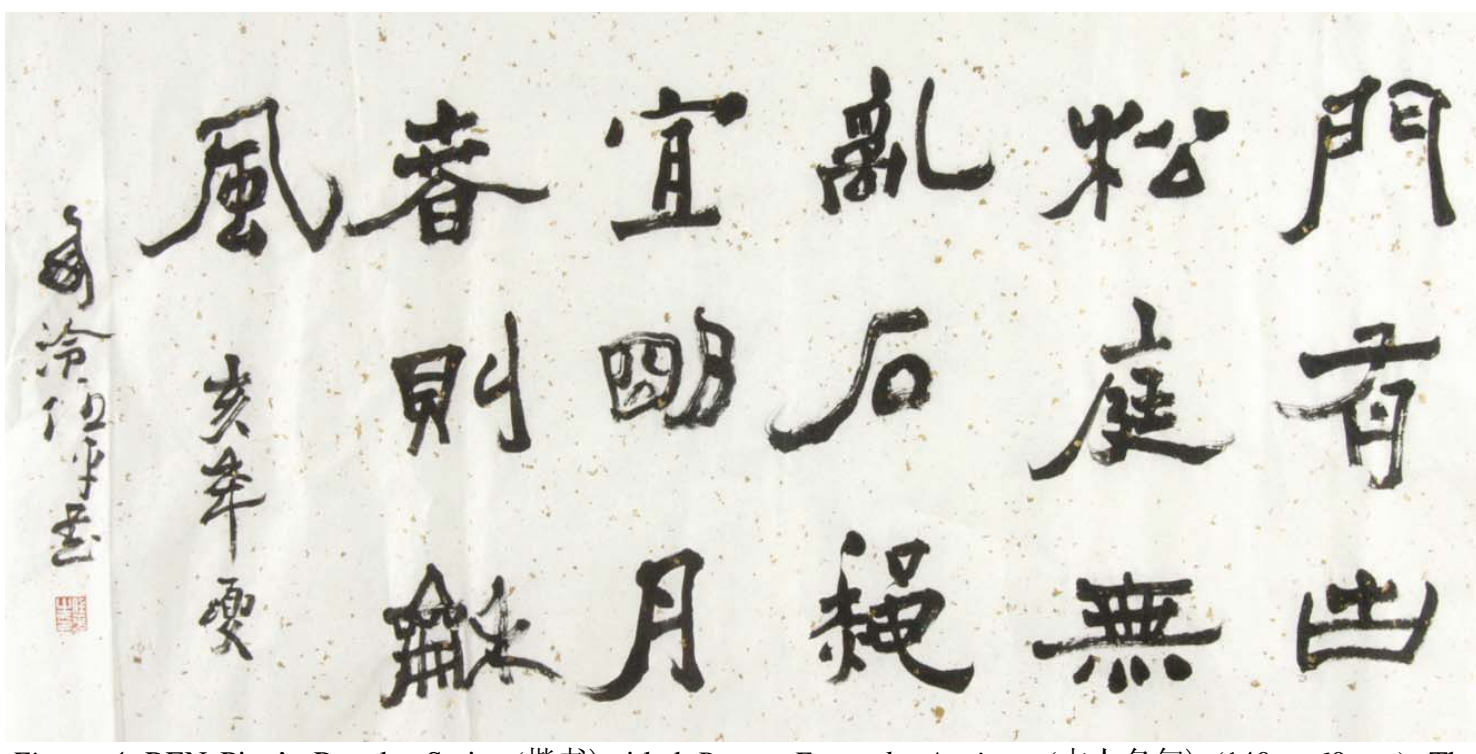

Figure 4. REN Ping's Regular Script (楷书) titled Poems From the Ancients (古人名句) $(140 \times 60 \mathrm{~cm})$. The photography was taken by Author in 2013.

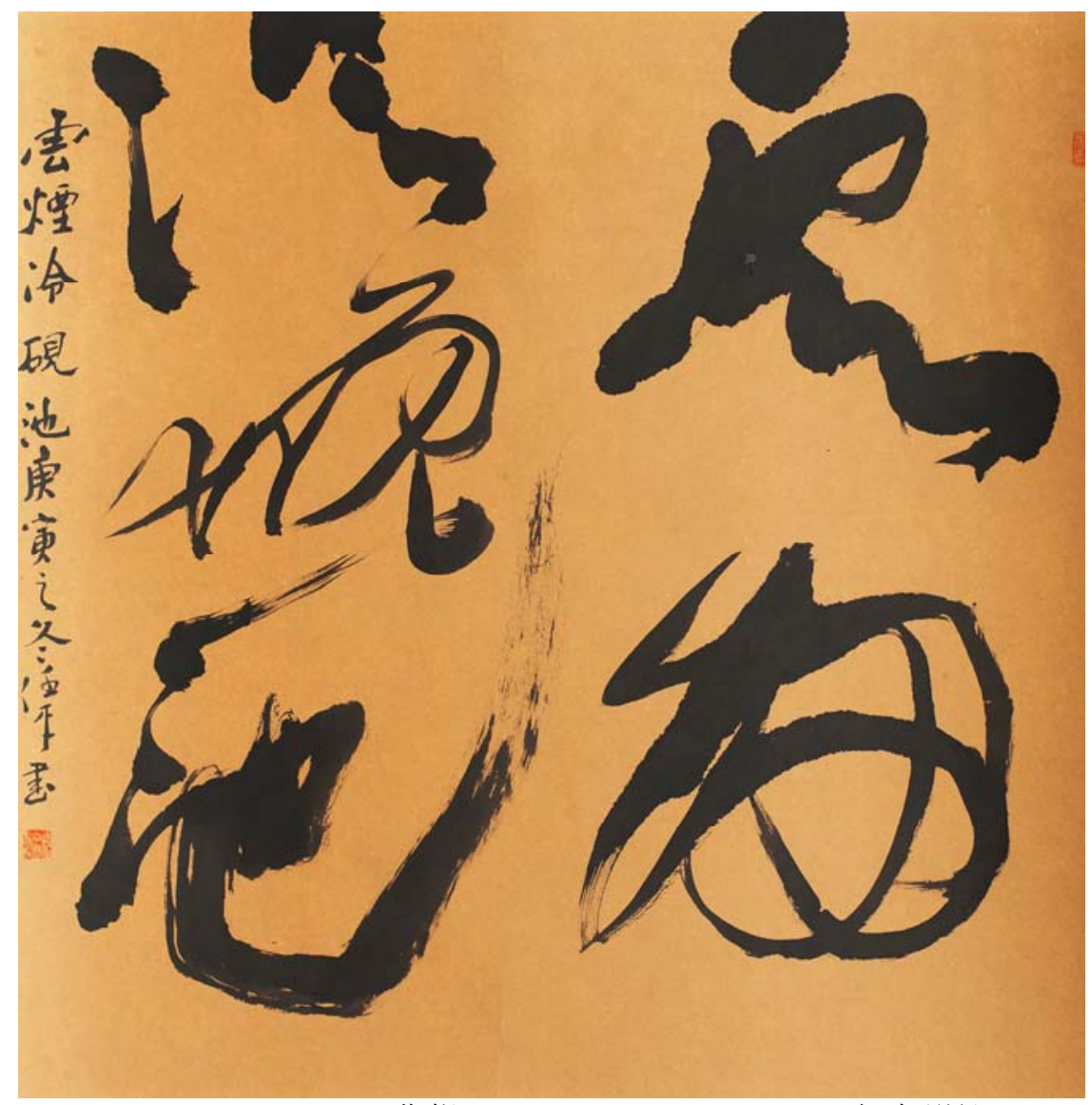

Figure 5. REN Ping' s Cursive Calligraphy (草书) titled Yun Yan Len Yan Chi (云烟冷砚池) $(120 \times 120 \mathrm{~cm})$ from The Contemporary Academic Calligraphy Masters Portfolio (当代书法学术名家作品集). Hong Kong: World Culture and Art Press. p. 42. 


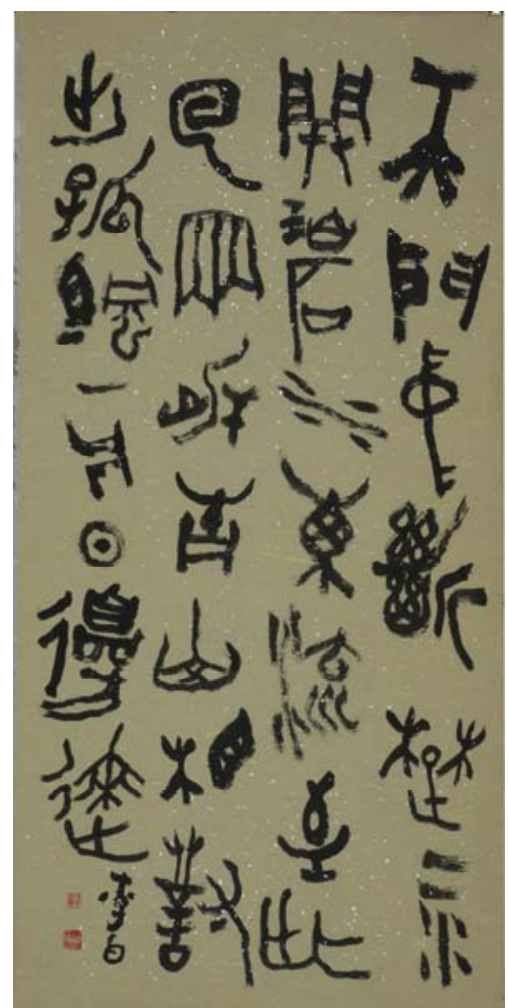

Figure 6. REN Ping's Seal Script Work (管书) titled Classic Chinese Poem of LI Bai: Tian Men Zhong Duan Chu Jiang Kai (李白诗: 天门中断楚江开) $(160 \times 80 \mathrm{~cm})$ from the Contemporary Academic Calligraphy Masters Portfolio (当代书法学术名家作品集). Hong Kong: World Culture and Art Press. p. 68.

\section{Application of Chinese Calligraphy in Contemporary Society}

REN Ping made a special trip to Beijing to write the title for the Chinese film The Flowers of War ${ }^{3}$ (see Figure 7). The five Chinese characters are derived from the "clerical and seal transformation script”, which lends a unique classical style to the movie. In accordance with the film's plot, he designed a special combination of the five characters forming the title, successfully retaining the imprints of ancient calligraphy. The last down-right stroke of the character CHAI seems not only like a sword, but also like a gold hairpin for women. It is full of artistic creation and it fits well with the environment of the film. In 2011, REN Ping said in an interview with reporters, "The clerical and seal transformation script represents a transition from the clerical script to the seal script. It made its appearance on the bamboo slips in northwest China from the Qin Dynasty to the Western Han Dynasty".

Chinese characters are hieroglyph, and so Chinese calligraphy has an ideographic function. As the meaning of calligraphy is full of abstract and Classic Chinese Literate connotations, the writing of Chinese calligraphy focuses on creating artistic and abstract shapes, and embodies the beauty of traditional Chinese aesthetics. Chinese calligraphy is the carrier of the well-grounded Chinese culture. It is people's consensus that the Chinese language is a kind of pictograph that enables the reader to appreciate its meaning, and that as a result, the

\footnotetext{
${ }^{3}$ Chinese Film The Flowers of War was shown in major Chinese cities and American mainstream commercial cinemas such as the New York, Los Angeles, and San Francisco.
} 
calligrapher can focus on the layout, structure and other artistic expressions of abstract beauty while creating an artistic work and, at the same time, filling the work with his understanding of a character's meaning. It can be seen therefore that the shape and meaning of traditional calligraphy complement each other and have rich cultural connotations. Its aesthetic system dates back to ancient Chinese philosophical thoughts and national aesthetic habits. It is obvious that REN Ping, the calligrapher has gained a revelation through a long process of studying the rubbings from ancient stone inscriptions and researching into the ancient Chinese characters. It is this revelation plus his drive to engage in calligraphy invention that resulted in something that has been hailed as "extremely miraculous", "the acme of perfection” of calligraphy works.



Figure 7. REN Ping's clerical and seal transformation script (隶管体) titled Jin Ling Shi San Chai (金陵十三钔) from the Contemporary Academic Calligraphy Masters Portfolio (当代书法学术名家作品集). Hong Kong: World Culture and Art Press. p. 52.

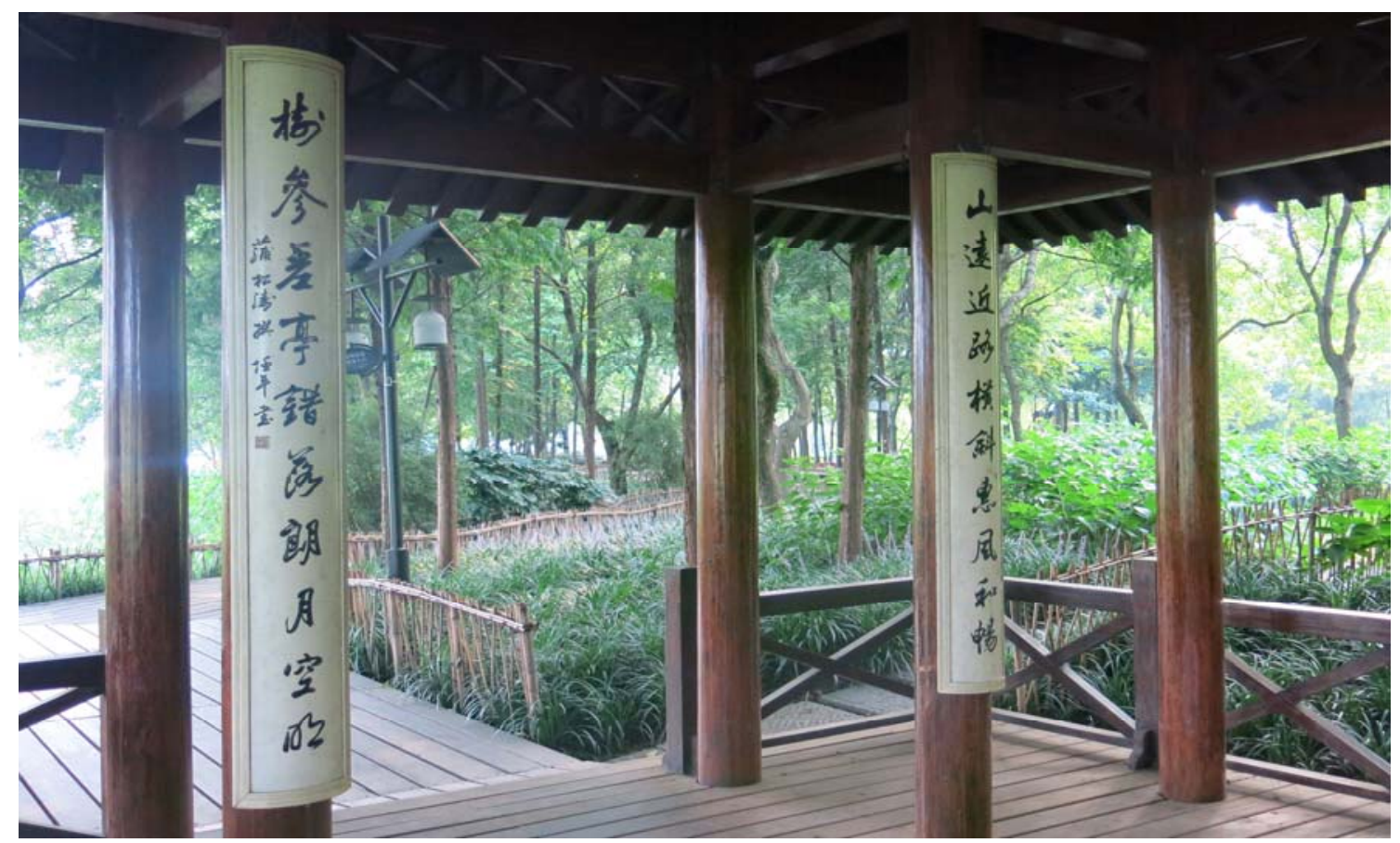

Figure 8. REN Ping calligrapher' s work was used in the Pavilion of ZONG XIU architecture. The photography was taken by author in Hangzhou on 6th August 2014. 
My hometown Hangzhou boasts of the scenic area of the West Lake, which has been placed in the UNESCO "World Heritage List", what I'd like to mention here is a wonderful poem inscription about the beauty of West Lake Landscape in the Pavilion of ZONG XIU (see Figure 8). The poem inscription is a calligraphy work of none other than REN Ping. It gives one a feeling of a board and wide beauty of nature with magnificence visible in mildness. It is clear, bright, vigorous, freewheeling and delectable, a work of art that is well worth careful scrutiny and repeated study.

\section{Conclusion}

All in all, Chinese calligraphy is an abstract art that connects meaning and reason, form and shape, form and meaning. It is a form of vocabulary that is recognizable, understandable, and internationalized. The form beauty of Chinese calligraphy is one of still, intuitive beauty, but it could be transformed into a dynamic spirit-resonance beauty. It gives expression to the classical Chinese aesthetics characterized by inherent spirit-resonance, blend of heart and matter, and the thought prior to writing or painting. Calligraphy works, while accompanying the serious artistic sentiments in development, rose above the basic functions of expressing meanings, relaying messages, and recording events. Here, the REN Ping calligrapher's thoughts and feelings are expressed by pure lines, inks, spaces, and movements, thus displaying the Drawing Essence from Ancient to Nourishing the New.

As a professor in the Chinese National Academy of Arts, the highest institute of Chinese calligraphic research, REN Ping has proved himself to be a famous calligrapher with a deep knowledge of exegetics and outstanding literary accomplishment. Not only does the formation of his calligraphy style come out of his special life path and learning experience as well as the cultural environment at a special time, but it stems from his contemplations about the tradition of Chinese calligraphy in its entity and its relevance to the modern times. It results from, his accumulation of Chinese traditional culture, his rich knowledge in occidental philosophy and art, his outstanding artistic talents, and from his generosity, forthrightness and sincerity, and his all-embracing humanistic feelings. His calligraphy art influences not only the contemporary Chinese people, but also contemporary Westerners.

\section{References}

JIANG, L. F. (1999). Study of ancient characters (古文字学). Kun Ming: Yunnan Renmin Chubanshe.

Lezzi, A. (2013). Contemporary Chinese calligraphy between tradition and innovation. Journal of Literature and Art Studies, 3(3), 176-77.

Li, W. D. (2009). Chinese writing and calligraphy. Hawai'i: University of Hawai'i Press.

REN, P. (1997). Storytelling of official script (说隶). Hangzhou: Zhejiang University Press.

REN, P. (2012). The contemporary Academic calligraphy masters portfolio一REN Ping (当代书法学术名家作品集: 任平). Hong Kong: World Culture and Art Press.

REN, P. (2014). Lecture outline of Kobe University (在日本神户大学的演讲纲要). From the REN Ping Calligraphy and Painting Series (任平书画文从). Hefei: Anhui Fine Arts Publishing House. 